\title{
Muscle contraction: theory and facts
}

\section{Valentin Borkhvardt}

Department of Vertebrate Zoology, Faculty of Biology, Saint Petersburg State University, Universitetskaya nab., 7-9, Saint Petersburg, 199034, Russian Federation

Address correspondence and requests for materials to Valentin Borkhvardt, borkhvardt@mail.ru

\begin{abstract}
All living organisms and many of their parts are organised in an essentially similar manner: they are closed cavitary bodies. This organisation allows living bodies to change shape by employing hydrostatic forces. It was recently shown that the hydrostatic mechanism lies in the basis of very different morphogenetic processes, and in the basis of muscle contraction, as recently shown by Borkhvardt (2017). The new hypothesis on the mechanism of muscle contraction explained many issues, but lacked direct proof. Now it seems that such proof has been found.
\end{abstract}

Keywords: muscle contraction, hydrostatic mechanism.

The theory of muscle contraction has been developed using evidence from striated muscle fibres, which have a very strict internal organisation. Their contractile unit is the sarcomere. It is represented by a three-dimensional lattice composed of thick myosin filaments and thin actin filaments arranged in parallel to each other. Actin filaments are attached to Z-disks separating the neighbouring sarcomeres. Contraction results from interaction of actin and myosin filaments. The heads of myosin molecules are assumed to be the motors converting chemical energy into mechanical energy. These heads attach to actin filaments and detach from them periodically in the course of contraction. Having attached, myosin heads turn and pull actin filaments towards the middle of the sarcomere. Z-disks follow the filaments, and the sarcomere shortens. This scheme is known as the sliding filament model.

This model invites quite a number of critical remarks (see Borkhvardt, 2016, 2017). In particular, it should be remembered that no one has actually observed the movement of myosin heads; the entire scheme is, therefore, merely a hypothesis. Smooth muscle cells do not possess a sarcomere organisation at all, and how they contract remains a mystery. Finally, the main objection is this. If muscular force is generated by molecular motors, it should be directly proportional to the number of these motors (myosin heads) and thus to the size of the muscle, its thickness and length. In reality, the force produced by a muscle does not correlate with its length, i.e., it does not depend on the number of molecular motors. The force correlates only with the muscle thickness. More precisely, it is directly proportional to the area of the physiological section of the muscle, which is perpendicular to the longer axis of muscle fibres or smooth muscle cells. Muscle force is calculated per unit area of this section, e.g., $\mathrm{kgf} / \mathrm{cm}^{2}$. This fact disproves the concept of molecular motors and with it the entire modern theory of muscle contraction. At the same time, it points to a new way to solve the problem. "Biological forces from muscle are proportional to the cross-section of the muscle, and scale as $\left[\mathrm{s}^{2}\right]$. Pneumatic and hydraulic forces are caused by pressures $(\mathrm{P})$ and also scale as $\left[\mathrm{s}^{2}\right]$ " (Trimmer, 1989, p. 274). The new way, as we see, leads us into the field covered by hydrostatic forces. 
It has long been known that the force of a muscle is proportional only to the area of its cross-section (physiological section). However, none of the supporters of the molecular motor hypothesis have paid any attention to it. Strangely enough, I also disregarded this fact for a long time. I say "strangely enough" because it was the hydrostatic model that I followed in my studies: the new hypothesis of muscle contraction (Borkhvardt, 2009) assumed that it occurred under the impact of external pressure.

This hypothesis was born as an expansion of my general ideas about mechanical transformations of living organisms (see Borkhvardt, 2002a, 2002b, 2009, 2010, 2016, 2017). In short, these ideas are as follows. All living organisms and many of their parts are organised in an essentially similar manner: they are closed cavitary bodies. A cavitary body consists of two parts: 1) the inner mass and 2) the sheath serving as a mechanical barrier between the inner mass and the environment (the outer mass). A change in the size and shape of cavitary bodies always results from the interaction of three components: 1) the inner mass, 2) its sheath and 3) the outer mass. Actively taking up and taking out substances first of all, water - a cavitary body changes the volume of the inner mass, in this way creating and regulating the difference between the internal and the external hydrostatic pressure. The inner (the outer) mass tends to move into the zone of lesser pressure, overcomes the resistance of the sheath, displaces it outwards (inwards) and moves together with it. Displacements occur earliest or only at the sites where the sheath offers the least resistance to the pressure. These local displacements change the shape of the body or its parts.

A universal model describing transformations of cavitary bodies has been referred to as the hydromechanical model (Borkhvardt, 2002a, 2002b). It embraces a broad range of morphogenetic processes: development of cell outgrowths, limb buds, gut derivatives and sense organs; endocytosis; cell division; branching of capillaries; gastrulation; cell locomotion; and muscle contraction. One might wonder whether the inclusion of sarcomeres into this list is justified since they do not have a sheath and are not closed bodies. I have given the corresponding justifications before and will not repeat them now so as not to digress from the topic.

The fact that the force developed by a muscle correlates with the area of its physiological section has been accounted for in recent publications (Borkhvardt, 2016, 2017), which has strengthened the case for the hydrostatic hypothesis of muscle contraction. Nevertheless, it remained based on indirect evidence. The hypothesis explained many issues - in particular, the functional features of smooth muscle cells - but it still lacked direct proof. Now I am ready to provide such proof. Surprisingly, it is also based on facts that have been common knowledge for many years.
It is known that the efficiency of skeletal musculature decreases considerably high in the mountains: the greater the altitude, the poorer muscle performance. This has a direct effect on the physical activity of mountaineers. For instance, they spend several hours scaling the last hundreds of meters to the peak of Mount Everest (8848 $\mathrm{m}$ above sea level), though the route is not particularly difficult and quite well equipped. It is generally thought that the low oxygen level in the thin air of the mountaintops is the cause. However, most climbers use oxygen masks at least at the final stage of the ascent, i.e., they do not experience an oxygen deficit. Nevertheless, people move with great difficulty, as I had a chance to observe watching a documentary about a climb to the top of the world. Images from this documentary made me realise the importance of facts I had long known theoretically. In truth, knowing and understanding are two different matters altogether.

So, why do muscles lose force at high altitude? Apart from the lack of oxygen, there is only one factor that might influence their performance there - low atmospheric pressure. At $7000 \mathrm{~m}$ the atmospheric pressure is only ca. $40 \%$ of that at sea level $\left(0.4 \mathrm{~kg} / \mathrm{cm}^{2}\right)$, while at $9000 \mathrm{~m}$ it is $30 \%\left(0.3 \mathrm{~kg} / \mathrm{cm}^{2}\right)$. Using oxygen masks to breathe freely, climbers in fact perform an experiment, the results of which show directly that low atmospheric pressure is the cause of muscle weakness at high altitude. A general conclusion follows: muscles contract under the impact of external pressure.

Low atmospheric pressure should have an effect not only on the work of muscles moving the body, but also on that of all other muscles. Poorer performance of diaphragm and chest muscles may render breathing difficult and lower its effectiveness. The same can be said about the heart muscle. In general, the performance of an organism at high altitude undergoes multiple changes, and low atmospheric pressure might be the cause of many of them.

To sum up, two facts revolutionise the theory of muscle contraction. Let us recount them: 1) muscle force is directly proportional to the area of the crosssection of a muscle cell or a muscle fibre and does not depend on their length; 2) high in the mountains, where atmospheric pressure is low, skeletal muscles perform poorly even when the organism gets a sufficient supply of oxygen.

\section{References}

Borkhvardt, V. G. 2002a. Gidromekhanicheskaya model formoobrazovatelnykh protsessov [Hydromechanical model of the morphogenetic processes]. Vestnik Sankt-Peterburgskogo Universiteta, Series 3. Biologia. (3):3-21. 
Borkhvardt, V. G. 2002b. Vpyachivaniya i vypyachivaniya: gidromekhanicheskaya model [Invagination and evagination: a hydromechanical model]. Ontogenez 33(1):19-27.

Borkhvardt, V. G. 2009. Mekhanicheskie preobrazovaniya zhivykh polostnykh tel [Mechanical transformations of living cavitary bodies]. 71 pp. Izdatelstvo TESSA, Saint Petersburg.

Borkhvardt, V. G. 2010. Mekhanicheskie preobrazovaniya zhivykh polostnykh tel [Mechanical transformations of living cavitary bodies]. Second Edition. 135 pp. Izdatelstvo TESSA, Saint Petersburg.
Borkhvardt, V. G. 2016. Mekhanicheskie preobrazovaniya zhivykh polostnykh tel [Mechanical transformations of living cavitary bodies]. Third Edition. 140 pp. Izdatelstvo Rossiiskogo gosudarstvennogo pedagogicheskogo universiteta imeni A. I. Gertsena, Saint Petersburg.

Borkhvardt, V. 2017. Mechanical transformations of living cavitary bodies. Biological Communications 62(2):103155. https://doi.org/10.21638/11701/spbu03.2017.206

Trimmer, W.S. N. 1989. Microrobots and micromechanical systems. Sensors and Actuators 19:267-287. https://doi. org/10.1016/0250-6874(89)87079-9 